\section{A degradable esophageal stent in the treatment of a corrosive esophageal stenosis in a child}

A 10-year-old boy accidentally ingested drain cleaner $(15 \% \mathrm{NaOH}$ solution; $\mathrm{pH}$ 12.5) from a bottle. He vomited and developed dysphagia and retrosternal pain. Endoscopy showed major circumferential ulcerations (grade IIb) [1]. Follow-up endoscopy after 4 weeks showed a stenosis at the mid esophagus, allowing passage of a neonatal endoscope (diameter $4.9 \mathrm{~mm}$ ). A self-expandable, biodegradable SX-Ella esophageal stent (diameter $25 \mathrm{~mm}$, length $80 \mathrm{~mm}$; Ella-CS, s.r.o., Hradec Králové, Czech Republic) was inserted 6 weeks after the ingestion with the patient under anesthesia ( $\bullet$ Fig. 1). Retrosternal pain, dysphagia, and nausea occurred for a few days. About 10 days later, the boy became asymptomatic. During all this time, oral omeprazole ( $20 \mathrm{mg} /$ day) was given. Further follow-up endoscopy after 3 weeks showed that the distal end of the stent had extended into the stomach ( Fig. 2). About 12 weeks after insertion, the stent was $50 \%$ degraded. At that time, the esophageal mucosa had healed. Although the patient remained symptom-free for 4 months, he developed a severe distal esophageal stenosis over $4 \mathrm{~cm}$ about 10 months after the initial ingestion and 6 months after the stent placement.

Strictures typically develop during proliferation of fibroblasts, with deposition of collagen after 1-3 months. Stenting, which has been performed for more than 20 years, provides a better outcome than dilation (68\% healing versus 33\%) [2,3]. Poor patient compliance and gastroesophageal reflux resulting from esophageal shortening during scar formation were the reasons for failure [3]. In another reported series 8 out of 11 patients had a normal feeding pattern, even after stent removal (follow-up 3.5 years) [4]. Self-expanding stents are easily introduced and are removed endoscopically. Common complications of these stents are chest pain, dysphagia, and nausea [5]. Recently, biodegradable stents were developed which maintain their integrity and radial force for 6-8 weeks. Disintegration occurs $11-12$ weeks after inser-

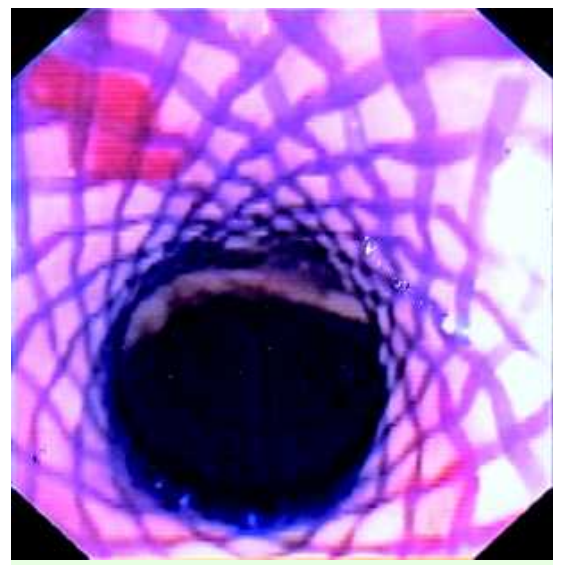

Fig. 1 View of the stent immediately after esophageal insertion.

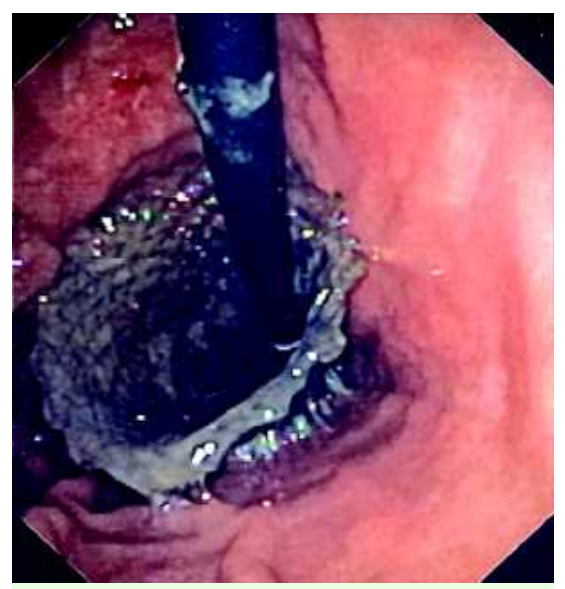

Fig. 2 Retrograde view of the stent protruding into the stomach after 3 weeks.

tion. The SX-Ella esophageal degradable BD Stent should be further evaluated as first-choice intervention in patients developing a corrosive esophageal stenosis.

Endoscopy_UCTN_Code_TTT_1AO_2AZ

\section{Y. Vandenplas ${ }^{1}$, B. Hauser ${ }^{1}$, T. Devreker ${ }^{1}$,} D. Urbain ${ }^{2}$, H. Reynaert ${ }^{2}$

Unit of Pediatric Gastroenterology,

Universitair Ziekenhuis Brussel Kinderen, Brussels, Belgium

Department of Gastroenterology, Universitair Ziekenhuis Brussel, Brussels, Belgium

\section{References}

1 Zargar SA, Kochhar R, Mehta S, Mehta SK. The role of fiberoptic endoscopy in the management of corrosive ingestion and modified endoscopic classification of burns. Gastrointest Endosc 1991; 37: 165-169

2 Coln D, Chang JH. Experience with esophageal stenting for caustic burns in children. J Pediatr Surg 1986; 21: $588-591$

3 Mutaf 0 . Treatment of corrosive esophageal strictures by long-term stenting. J Pediatr Surg 1996; 31: 681-685

4 Atabek C, Surer I, Demirbag S et al. Increasing tendency in caustic esophageal burns and long-term polytetrafluroethylene stenting in severe cases: 10 years experience. J Pediatr Surg 2007; 42: 636-640

5 Holm AN, de la Mora Levy JG, Gostout CJ et al. Self-expanding plastic stents in treatment of benign esophageal conditions. Gastrointest Endosc 2008; 67: 20-25

Bibliography

DOI 10.1055/s-0029-1214437

Endoscopy 2009; 41: E73

(c) Georg Thieme Verlag KG Stuttgart · New York . ISSN 0013-726X

\section{Corresponding author}

\section{Y. Vandenplas, MD, PhD}

UZ Brussel Kinderen

Laarbeeklaan 101

1090 Brussels

Belgium

Fax: +3224775783

yvan.vandenplas@uzbrussel.be 